\section{Discussion}

This case history is of interest because of the diagnostic problems presented by the onset of haematuria during the course of severe staphylococcal septicaemia treated with massive doses of penicillin, since it may be a complication both of the disease and of the therapy. Haematuria may arise during the course of staphylococcal septicaemia but in this patient the onset was later than the height of the infection, and haematuria resulting from infection is usually associated with pus cells in the urine. There are on record two cases of haematuria during probenecid therapy (Boger \& Strickland, 1954) where it was ascribed directly to the uricosuria rather than to drug sensitivity, but in our case the dose was low and the duration of treatment short. When the probenecid was discontinued the haematuria diminished. However, it again increased when the daily intravenous dose of methicillin was raised from $12 \mathrm{~g}$ to $16 \mathrm{~g}$. The persistence of the haematuria coupled with the continued fever despite clinical recovery suggested a methicillin sensitivity. Following reduction of the intravenous methicillin to $8 \mathrm{~g} /$ day, the haematuria again temporarily decreased and gradually stopped after the drug was discontinued. It seems likely that the temporary fall in the degree of haematuria after stopping the probenecid was due to a fall in the blood levels of methicillin at that time.

Baldwin et al., (1968) described the syndrome of hypersensitivity as characterized by fever, evanescent morbilliform rash, haematuria, azotaemia and eosinophilia. Our patient showed all these features.
Of their seven patients four were on doses of methi- $\cong$ cillin ranging from 7 to $24 \mathrm{~g} /$ day and demonstrated 3 some or all of these features. All recovered after $\stackrel{\varnothing}{\varrho}$

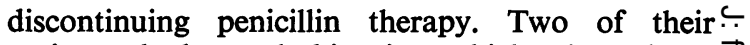
patients had renal biopsies which showed an $\overrightarrow{\vec{F}}$ insterstitial nethritis with tubular damage but no? evidence of glomerular lesion or arteritis. This $\frac{\mathrm{C}}{\mathrm{C}}$ hypersensitivity only appears to develop in patients $\frac{\bar{\sigma}}{\frac{\omega}{6}}$. given high doses of methicillin over prolonged $\vec{\nabla}$ periods and the allergen has been postulated as $a \varrho$ penicillin hapten/renal protein. The delayed hypersensitivity skin test (Redmond \& Levine, 1968) $\vec{\circ}$ appears to have little diagnostic usefulness since it is present in $21 \%$ of patients who have no recent $\vec{\omega}$ exposure to penicillin and who can tolerate penicillin $\frac{\sigma}{\delta}$ without allergic reactions.

It may be of interest to note that no difficulties or side-effects were noted while doses of fusidic acid. were given in the form of a new preparation in the maximum doses ( $2 \mathrm{~g} /$ day).

\section{Acknowledgments}

We would like to thank Dr T. M. Chalmers for his advice and for his permission to publish this case.

\section{References}

BaldWin, D.S., LeVINE, B.B., McCluSKy, R.T. \& Gallo, $\vec{\oplus}$ G.E. (1968) Renal failure and interstitial nephritis due of penicillin and methicillin. New England Journal \$f Medicine, 279, 1245.

BOGER, W.P. \& STRICKLAND, S.C. (1954) Corresponden on gout. Lancet, i, 420.

REDMOND, A.P. \& LEVINE, B.B. (1968) Delayed skin reactions to benzyl penicillin in man. International Archives of Allergy and Applied Immunology, 33, 193.

\title{
Osteogenesis imperfecta in a child presenting with neurological features
}

\author{
N. A. P. Evans* \\ M.B., M.R.C.P., D.C.H., D.Obst.R.C.O.G. \\ Hospital for Sick Children, Great Ormond Street, \\ London, W.C.1
}

\begin{abstract}
Summary
A case of osteogenesis imperfecta presenting with a rare neurological complication (spastic paraplegia) is presented. The aetiology of the neurological lesion is discussed.

OSTEOGENESIS imperfecta is a systemic disease of the mesenchymal tissues of the body, which is inherited

* Present appointment: Pædiatric Registrar, Royal Alexandra Hospital for Sick Children, Dyke Road, Brighton. Sussex.
\end{abstract}

as an autosomal dominant characteristic with $\mathrm{a}$. variable degree of expression. The condition usually $\mathcal{N}$ presents in childhood with pathological fractures, $N$ bony deformities and blue sclerae. There is a wide N spectrum of severity. Clinical features less commonly seen include dislocated joints, opalescent teeth with defective dento-enamel junctions, (dentinogenesis imperfecta), otosclerosis and deafness. (Heys, Blattner \& Robinson, 1960). Neurological complications are rare. Single cases of osteogenesis imperfecta with neurological abnormalities have been reported $\mathbb{D}$ 
by Ray (1942) and by O'Connell \& Turner (1950), whilst Hurwitz \& McSwiney (1960) described four cases, all members of one family. Only two of these six patients presented in childhood.

A further case of osteogenesis imperfecta presenting with a neurological complication is reported.

\section{Case report}

M.R. a female infant was the first born to healthy unrelated parents. Delivery was normal following an uneventful pregnancy of 41 weeks' duration. The birth weight was $3 \cdot 1 \mathrm{~kg}$. There were no neonatal complications. She presented at the age of 2 years 11 months because of an inability to walk, although she was able to move around the furniture by supporting herself on her arms. She did not stand until $2 \frac{1}{2}$ and had never crawled. All other aspects of her development were normal including satisfactory control of urine and faeces. During the first year only feeble kicking of the legs had been noted and abduction of the hips had precipitated screaming attacks.

Examination revealed a bright attractive child who resented interference. Examination was only possible as part of a play sequence. There were no abnormalities in the cardiovascular, respiratory or alimentary systems, other than slight asymmetry of the chest cage. The teeth were normal. Her height and weight were on the 25th percentile and her head circumference on the 50th percentile. The neck was short. Neurological examination was as full as possible and showed no abnormalities of the cranial nerves, arms or trunk. In the lower limbs power was decreased, especially proximally; there was no wasting; tone was increased and tendon reflexes were pathologically brisk; the Babinski responses were equivocal; co-ordination and sensation were apparently normal and there was no crossed adductor jerk.

The parents and two younger male siblings (aged 20 months and 3 months) showed no abnormal neurological findings or clinical evidence of osteogenesis imperfecta, and their X-rays were normal.

Investigations. X-rays of the skull (Fig. 1) revealed wormian bones. There was a marked deformity of the foramen magnum with lateral elevation of its margins. Whereas there was no definitive radiological evidence of basilar impression it was thought that the deformity recorded would so progress. The pelvis was grossly deformed and of triradiate type (Fig. 2). The sacrum was curved anteriorly. The spine was normal. The lower limbs showed marked bowing. There was generalized osteopenia but no fractures. At the deltoid insertion on the humerus (Fig. 3), there was an irregularity of the bony cortex which was thought to represent ab-

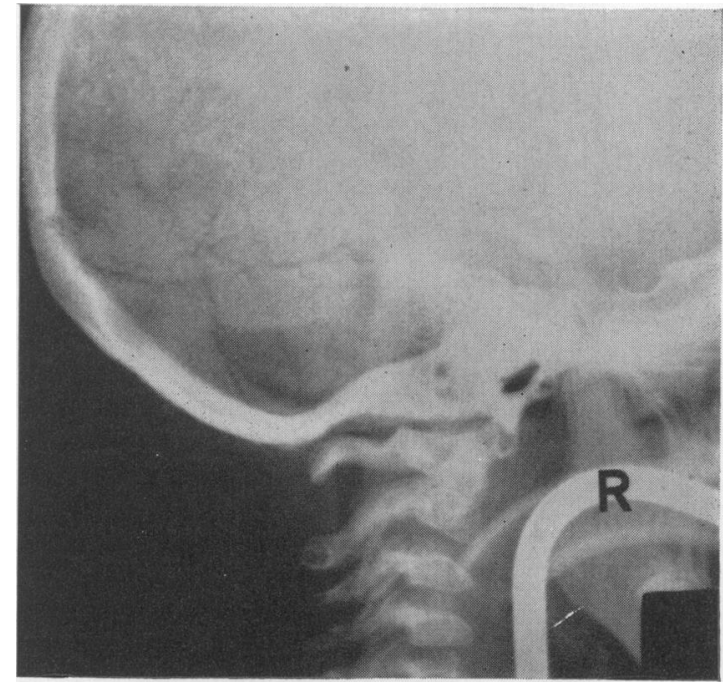

Fig. 1. X-ray of skull.

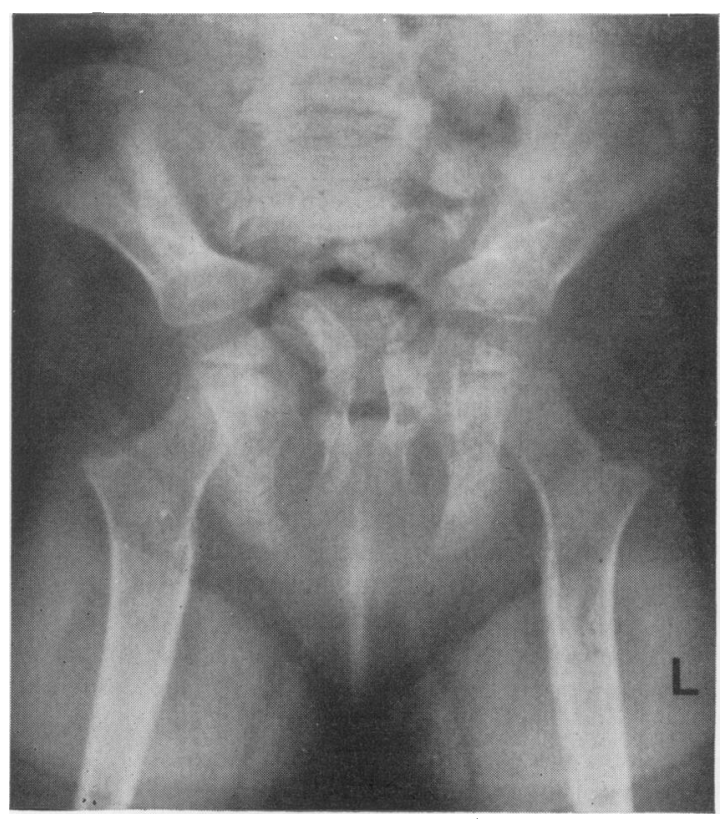

Fig. 2. X-ray of pelvis.

normal osteogenesis or collagen formation at the site of the tendon attachment. Similar changes were found at insertion sites on the lower limbs. An air myelogram and air encephalogram were normal. 


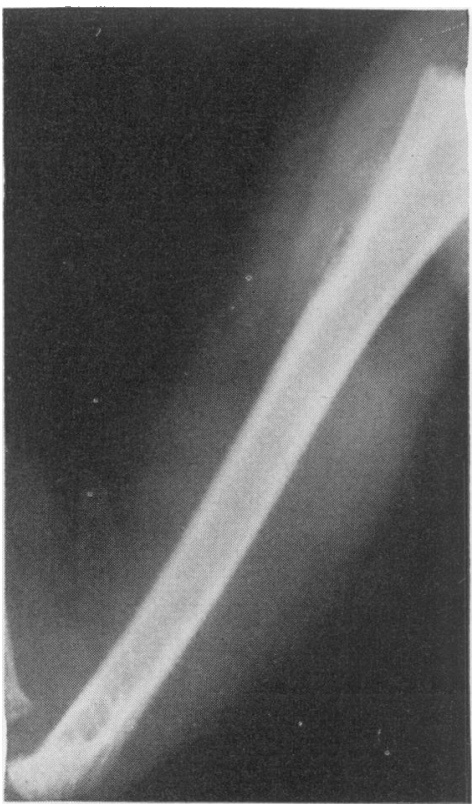

Fig. 3. X-ray of humerus.

Estimations of serum calcium, phosphorus and alkaline phosphatase levels were within normal limits. The protein in the cerebrospinal fluid was $10 \mathrm{mg} / 100 \mathrm{ml}$.

An electromyogram (right tibialis anterior) and nerve conduction studies (right lateral popliteal) were normal.

\section{Discussion}

The diagnosis of osteogenesis imperfecta was made radiologically on finding wormian bones (without evidence of cleido-cranial dysotosis or hypophosphatasia) in conjunction with generalized osteopenia and bowing (Caffey, 1967).

The deformity of the skull base was considered to represent an early stage of basilar impression, which is known to complicate osteogenesis imperfecta (Ray, 1942; O’Connell \& Turner, 1950; Hurwitz \& McSwiney, 1960). Basilar impression may be associated with herniation of the cerebellar tonsils and with syringomyelia. Cerebellar, sensory, upper and lower motor neurone signs and involvement of the cranial nerves of the posterior fossa may thus be seen with basilar impression (Ford, 气 1966). In the patient reported only upper motor $?$ neurone signs were apparent, but minor degrees of $\stackrel{\mathbb{Q}}{\complement}$ peripheral wasting and sensory changes may be $C$ difficult to detect in an unco-operative 3-year-old. $\overrightarrow{\vec{F}}$ The normal air myelogram and encephalogram $\stackrel{\oplus}{\rightarrow}$ exclude any severe pressure effect on the medulla or spinal cord, but a dural band at the foramen magnum or a small syrinx cannot be excluded. A change in the anatomical relationships at the base of the skull may also have caused secondary vascular changes in the medulla and cervical cord.

Hereditary spastic paraplegia cannot be excluded in this patient. However, it usually affects several siblings, it is more common in boys, and it rarely presents under the age of 3 . In view of these features it would seem to be an unlikely diagnosis, especially in the presence of osteogenesis imperfecta with $\unrhd$ abnormalities of the foramen magnum. There was or no other evidence of any cerebral or peripheral $\overrightarrow{0}$ lesion which might have been responsible for the $\frac{G}{N}$ paraplegia.

As the exact cause of this patient's neurological $\stackrel{\circ}{2}$ signs remains obscure and an operative decompression may be required later, it is planned to keep her under close review. Further neuroradiological studies, including angiography, will be considered of there is any deterioration.

\section{Acknowledgments}

I should like to thank Dr K. S. Holt under whom the patient was admitted, for helpful advice and criticism. Several members of the consultant staff at the Hospital for Sick Children, Great Ormond Street, saw the patient in $\varrho$ consultation and I am grateful for their opinions.

\section{References}

CAffey, J. (1967) Pediatric $X$-ray Diagnosis, 5th edn, p. 52. Year Book Medical Publishers Inc., Chicago.

FORD, F.R. (1966) Disease of the Nervous System in Infancy, Childhood and Adolescence. 5th edn, p. 131. Thomas, Springfield.

Heys, F.M., Blattner, R.J. \& Robinson, H.B.G. (1960) Osteogenesis imperfecta; clinical and genetic aspects in $\delta$ eighteen families. Pediatrics, 56, 234.

HuRwitz, I.J. \& MCSwiney, R.R. (1960) Basilar impression 0 and osteogenesis imperfecta in a family. Brain, 83, 138.

O'Connell, J.E.A. \& TuRner, J.W.A. (1950) Basilar im- $\frac{D}{O}$ pression of the skull. Brain, 73, 405. RaY, B.S. (1942) Platybasia with involvement of the Central $N$
Nervous System. Annals of Surgery, 116, 231 . 